ENCYCLOPÉDIE Encyclopédie berbère

BERBERE

5 | 1988

5 | Anacutas - Anti-Atlas

\title{
Ancorarius ou Anchorarius mons
}

$\mathrm{Ph}$. Leveau

\section{OpenEdition}

Journals

Édition électronique

URL : http://journals.openedition.org/encyclopedieberbere/2498

DOI : 10.4000/encyclopedieberbere.2498

ISSN : 2262-7197

\section{Éditeur}

Peeters Publishers

\section{Édition imprimée}

Date de publication : 1 avril 1988

Pagination : 636-637

ISBN : 2-85744-379-6

ISSN : 1015-7344

\section{Référence électronique}

Ph. Leveau, «Ancorarius ou Anchorarius mons », Encyclopédie berbère [En ligne], 5 | 1988, document A214, mis en ligne le 01 décembre 2012, consulté le 17 octobre 2020. URL : http:// journals.openedition.org/encyclopedieberbere/2498; DOI : https://doi.org/10.4000/ encyclopedieberbere. 2498

Ce document a été généré automatiquement le 17 octobre 2020

(c) Tous droits réservés 


\title{
Ancorarius ou Anchorarius mons
}

\author{
$\mathrm{Ph}$. Leveau
}

1 Nom d'une montagne de Maurétanie Césarienne qui apparaît dans deux textes: Pline l'Ancien, XIII, 95 à propos du citrus et Ammien Marcellin XXIX, 5, 17, dans le récit de la guerre contre Firmus.

2 Ce nom semble dérivé du latin ancora et ne présenter aucun caractère indigène. Mais on ne peut dire s'il s'agit de la traduction latine d'un toponyme indigène ou d'un toponyme forgé pour une raison qui nous échappe. Pourtant F. Khadra (Les Djeddars, monuments funéraires de la région de Frenda, Alger, 1983, p. 244-245) signale une marque de tâcheron Acorariu qu'elle rapproche d'Ancorarius.

3 Le texte de base est celui d'Ammien Marcellin qui décrit le déroulement des opérations de Théodose et localise cette montagne par rapport à Castellum Tingitanum (El Asnam, ex-Orléansville) : «Théodose s'avança jusqu'à Castellum Tingitanum; puis, franchissant le Mons Ancorarius il attaque les Mazices et Fericius, préfet de la tribu qui avait aidé le parti du perturbateur de la tranquillité publique... » (Ammien Marcellin, XXIX, 5, 17). Les Mazices sont relativement bien localisés dans la vallée du Chélif; deux textes épigraphiques en particulier les y mentionnent (Ph. Leveau, L'aile II des Thraces, les Mazices et les praefeti Gentis en Afrique du nord, Antiq. Afric, t. 7, 1972, p. 171-175, où j'admettais l'identification de l'Ancorarius et de l'Ouarsenis). Malheureusement Ammien Marcellin ne dit pas si Théodose s'est dirigé vers le nord ou vers le sud. Allant vers le sud, il aurait franchi l'Ouarsenis qui serait l'Ancorarius et attaqué les Mazices dans le Sersou. Dans l'autre cas, il aurait traversé vers le nord la vallée du Chélif, pour attaquer les Mazices, à l'intérieur du massif littoral ; le mons Ancorarius serait soit la montagne qui sépare la vallée du Chélif de la dépression de l'oued Hamelil coulant de Beni Naria (ex- Flatters) à Damous (c'est-à-dire la montagne de Medjadja), soit celle qui, plus à l'ouest, borde la plaine du Chélif (région de Kalaa et Timici). L'identification de l' Ancorarius avec un élément des chaînes littorales semble préférable à celle proposée par Ed. Cat entre l'Ancorarius et l'Ouarsenis (Essai sur la province romaine de Maurétanie césarienne, Paris, 1891, p. 21) et à propos de laquelle St. Gsell exprimait son scepticisme (St. Gsell: Société archéologique du département de Constantine, Souvenir du Cinquantenaire, t. XXXVI du R.S.A.C., 1902, p. 36 et Atlas archéologique de l'Algérie, Alger, 
1911, f. 23, 1). En effet une localisation des Mazices dans le Sersou est peu vraisemblable, même si l'on imagine qu'ils fuyaient.

Par contre l'identification proposée n'est pas en contradiction avec le texte de Pline l'Ancien Ancorarius mons vocatur citerioris Mauretaniae, qui laudatissimum dedit citrum iam exhaustus (XIII, 95). Il n'y a aucune raison de traduire comme A. Ernout (Les Belles Lettres, éd. Budé, p. 49) citerior par l'intérieur ; citerior se comprend par référence à ulterior : la Maurétanie Citérieure est la Césarienne, l'Ultérieure est la Tingitane. En second lieu, le citrus (thuya de Barbarie ou Callittis articulata (Olk, R.E., III, 2, col. 2621-2624) n'est pas un arbre d'altitude car s'il supporte mieux la sécheresse que le pin d'Alep, il est sensible au froid; il peuple, dans l'ancienne Césarienne, le Dahra (c'est-à-dire en général la bande montagneuse s'étendant entre l'Oranie et la Mitidja), l'Ouarsenis occidental, les plateaux de Frenda et de Tlemcen, le Sahel d'Oran et les Trara (J. Despois, L'Afrique du nord, Paris, P.U.F., 1964, p. 89). L'Ouarsenis se prête donc moins bien que la zone montagneuse littorale à l'exploitation du citrus. En troisième lieu, et cela semble le point le plus intéressant, il est possible d'établir un rapport entre la vogue des tables de citrus et la pénétration romaine en Césarienne. Pline note que « Théophraste ne dit mot des tables de citrus et que l'on n'en mentionne nulle part avant celles de Ciceron; ce qui prouve qu'elles sont récentes " (XIII, 102). Or, à l'époque de Pline, le citrus de l' Ancorarius est épuisé tandis que l'exploitation continue ailleurs en Césarienne. Même si l'on dissocie conquête militaire et commerce, et même si l'on tient compte de la grande valeur de ce bois qui pouvait rendre son exploitation rentable malgré des transports longs et incertains, il semble peu vraisemblable que, bien avant la seconde moitié du $\mathrm{I}^{\mathrm{er}}$ siècle, les thuyas de l'Ouarsenis occidental aient été exploités jusqu'à épuisement de l'arbre. C'est moins étonnant pour une région proche de la mer et peu éloignée de la colonie augustéenne de Cartenae (Ténès) convenant parfaitement au thuya et de circulation relativement aisée. (Ph. Leveau, "Recherches historiques sur une région montagneuse de Maurétanie Césarienne, des Tigava castra à la mer », M.E.F.R.A., t. 89, 1977, p. 289-304 ; Id. Caesarea de Maurétanie, Paris, 1984, p. 496).

5 Une identification du Mons Ancorarius avec des petites montagnes mal individualisées sur les cartes modernes peut apparaître étonnante, mais elle s'accorde avec la bonne connaissance des régions littorales de l'Afrique par les Romains du premier siècle, qui transparaît dans la densité des sites portés pour cette région sur la carte de Ptolémée, même si bien souvent on ne parvient pas à les localiser exactement.

\section{INDEX}

Mots-clés : Algérie (partie nord), Antiquité 